\title{
Preconditioning of a secondary reinforcer
}

MARILYN E. MILLER, University of Wisconsin-Milwaukee, Milwaukee, Wis.

Using $40 \mathrm{Ss}$, an attempt was made to precondition a secondary reinforcer by pairing two lights during preconditioning, making the paired presentation of one of the lights and reinforcement contingent upon a button-pressing response during conditioning, and measuring the number of responses for presentation of the other light during extinction. Relative to controls, there was a preconditioning effect $(p<.05)$ which was more pronounced when $S$ was a dim light and the test stimulus a bright light $(p=$ $.025)$. The results suggest that the preconditioning effect is a more general phenomenon than previous research would indicate.

The term "sensory preconditioning" was introduced by Brogden (1939), and its use implies a fairly standard three-phase experimental procedure consisting of preconditioning (PC), conditioning, and test. During PC, several paired presentations of two, presumably neutral stimuli are given $S$; during conditioning, a response is conditioned to one of the $\mathrm{PC}$ stimuli; and during the test phase, the number of conditioned responses (CR's) to the other, unconditioned stimulus is measured. When preconditioned Ss make more CR's to the test stimulus than do Ss who were not preconditioned, (i.e., when preconditioning increases the transfer or generalization of acquired cue properties from the CS to the test stimulus) the preconditioning effect (PCE) is said to have occurred. As a phenomenon, PCE has been demonstrated both for animals (dogs, cats, rats) and for humans (including retardates). An extensive, though not necessarily exhaustive, review of the PC literature indicated that shock (or its threat) was used during most conditioning phases, with one of the PC stimuli serving as the CS either for an avoidance response or for the galvanic skin response. Apparently, the only experiment in which shock was not used as the UCS was conducted by Reid (1952) who, using pigeons as Ss, attempted to establish one of the PC stimuli as a discriminative stimulus for a pecking response. He found no evidence of PCE during the test phase.

Despite Reid's negative findings, the seeming lack of interest in PC within other kinds of conditioning paradigms is somewhat surprising. If, as has been fairly well established, PC increases the generalization of acquired cue properties of the CS, there seems to be no theoretical reason why the $\mathrm{PC}$ procedure should not similarly increase the generalization of other acquired stimulus characteristics.

The present experiment was a preliminary step toward determining the possible generality of $\mathrm{PCE}$ as a phenomenon, and was designed specificially to determine whether a secondary reinforcer $\left(S^{r}\right)$ could be preconditioned.

\section{METHOD}

Subjects. Forty undergraduate students from an introductory psychology course at the University of Wisconsin-Milwaukee were assigned to four groups. Course requirements included $3 \mathrm{~h}$ of participation in psychological experiments.

Apparatus. Each S was seated in semidarkness facing a flat-black $24 \times 24$ in. panel with a 3 in: wide shelf extending 6 in. forward from the bottom of the panel. A push-button was centered on the shelf, 2 in. forward from the backpanel, and was covered with a retractable metal plate. The face of an electric counter was centered $15 \mathrm{in}$. above the shelf and two frosted, plastic lenses were mounted immediately above and below the counter. The E could interchangeably mount a $7 \mathrm{~W}$ or a $15 \mathrm{~W}$ light bulb behind each lens.

Procedure. The Ss were told that they would be given an opportunity to earn additional experimental credit, and that the additional minutes would register on their counter. They were further told that a button, which they could press as often as they wished, would be presented sometime during the session, and that they could leave the experiment any time that they desired with no loss of experimental credit already gained. The experiment was conducted in three phases.

Preconditioning. For the experimental groups, two lights $\left(\mathrm{L}_{1}\right.$ and $L_{2}$ ) were presented together, with $L_{1}$-onset preceding the onset of $L_{2}$ by 1 sec. The lights overlapped for 1 sec and terminated simultaneously. There were 60 paired presentations with an intertrial interval (IT1) of 2 sec. For Group $D, L_{1}$ was the dimmer, $7 \mathrm{~W}$ light and $L_{2}$ was the $15 \mathrm{~W}$ light; for Group $B, L_{1}$ was the $15 \mathrm{~W}$ and $L_{2}$ the $7 \mathrm{~W}$ light. For the control groups, DC and BC, only $L_{1}$ was presented 60 times with a $2 \mathrm{sec}$ duration and a 2 sec ITI. Within each of the four groups, the position of $L_{1}$ and $L_{2}$ (above and below the counter) was counterbalanced. During this phase, the counter did not operate and the response button was covered.

Secondary reinforcement conditioning. Without interruption or additional instructions, the plate over the response button was retracted. Each button press resulted in the onset of $\mathrm{L}_{2}$. Two sec later, simultaneously with $\mathrm{L}_{2}$ 's offset, the counter advanced one unit. The button was inoperative while the light was on. All Ss received 30 paired presentations of $\mathrm{L}_{2}$ and reinforcement. This phase was the same for all groups except that $L_{2}$ was the bright light for Groups D and DC, and the dim light for Groups B and BC.

Extinction or test for $P C E$. Again without interruption or additional instructions, each button press now resulted in the onset of $L_{1}$ for a duration of $2 \mathrm{sec}$. The number of responses in each $30 \mathrm{sec}$ interval was recorded until one of the following three criteria was met: (1) $\mathrm{S}$ left the situation (or expressed a desire to do so); (2) no response was made within a $30 \mathrm{sec}$ interval; or (3) the test phase had lasted $15 \mathrm{~min}$.

\section{RESULTS}

Means, medians, and standard deviations of the total number of responses to extinction for each group are shown in Table 1. A 2 by 2 by 2 analysis of variance comparing number of responses to extinction for experimental vs control groups, for intensity of $L_{1}$, and for position of $L_{1}$, revealed a significant difference only between experimental and control groups $(F=4.70, \mathrm{df}=1 / 32$, $p<.05)$. However, the variances were significantly heterogeneous $\left(F_{\max }=10.36\right.$, df $\left.=4 / 9, \quad p<.01\right)$; therefore, Fisher's exact median test was used to compare each intensity group with its control. There was no difference between Groups D and DC, while the difference between Groups $B$ and $B C$ was significant $(p=.025)$.

\section{DISCUSSION}

The difference between Groups $B$ and $B C$ indicates that it is possible to precondition a secondary reinforcer. The lack of a similar difference between Groups D and DC, if not due to variability, suggests either that preconditioning of the dim light was not effective or that the bright light did not acquire reinforcing properties (or both). The latter alternative-that the bright light acquired reinforcing properties less effectively than did the dim light-seems contrary to expectations. However, the relative effectiveness of the bright and dim light as secondary reinforcers could be ascertained in subsequent $\mathrm{PC}$ research by including additional control groups for whom the test stimulus is the $S^{r}$. If bright and dim lights are equally effective as an $S^{r}$ and if the present findings are replicated (i.e., if Group B, for whom $\mathrm{S}^{\mathrm{r}}$

Table 1

Means, SDs, and Medians of Responses to Extinction

\begin{tabular}{|c|c|c|c|c|}
\hline & \multicolumn{2}{|c|}{$\begin{array}{l}\mathbf{S}^{\mathbf{r}}=\text { bright light } \\
\text { test light }=\operatorname{dim}\end{array}$} & \multicolumn{2}{|c|}{$\begin{array}{l}\mathrm{S}^{\mathrm{x}}=\operatorname{dim} \text { light } \\
\text { test light }=\text { bright }\end{array}$} \\
\hline & Group D & Group DC & Group B & Group BC \\
\hline Means & 227.7 & 162.4 & 221.2 & 70.1 \\
\hline SDs & 232.8 & 132.2 & 128.0 & 72.3 \\
\hline Medians & 132.5 & 139.0 & 232.5 & 46.5 \\
\hline
\end{tabular}


was a dim light and the test stimulus a bright light shows PCE and Group D, for whom $S^{r}$ was a bright light and the test stimulus a din light, does not), then it would seem that stimulus intensity affects the preconditioning process. The effect of intensity of PC stimuli has not previously been investigated, perhaps because most PC researchers have followed Brogden's basic design in using stimuli from two sense modalities, auditory and visual.

The present findings suggest that PCE is a more general phenomenon than previous research would indicate. As a process.
PC most certainly has theoretical implications which cannot be thoroughly understood without further and more general research in this area.

\section{REFERENCES}

BROGDEN, W. J. Sensory pre-conditioning. Journal of Experimental Psychology, 1939, 25, 323-332.

REID, R. L. A test of sensory pre-conditioning in pigeons. Quarterly Journal of Experimental Psychology, 1952, 4, 49-56. 